\title{
Too Entertaining to be True: Recent headlines declaring eight men are as wealthy as half the world misrepresent trends in inequality ${ }^{1}$
}

\section{By Ernesto F. L. Amaral and Carter C. Price}

Feb. 6, 2017, at 12:00 p.m.

The headlines reporting on a recent study about the world's wealth were pretty irresistible: The world's eight richest men are as wealthy as the poorest half of the population. That was quite a jump from the 2016 report, when the anti-poverty organization Oxfam International said it took 62 people to manage this feat. But the measure they used presents a misleading view of trends in inequality.

While these Oxfam reports have done a good job bringing attention to the problem of inequality, the main measure used for framing the analysis - wealth at the top versus the bottom - may give many the wrong impression. Much of the political and broader discussion of economic inequality has been focused on inequality within countries, but Oxfam's report focuses on comparing wealth globally. In this case, the focus on global inequality is a red herring.

Global inequality has actually been on the decline while inequality within the developed world is increasing. But that wouldn't necessarily be the quick takeaway from the Oxfam report, which presents a false narrative about trends in inequality. Why should this matter? Because a widely accepted misperception can lead to policy proposals that fail to address the problem of rising inequality within nations.

In reality, globalization has pulled hundreds of millions out of poverty and led to a reduction in global inequality. Between 2002 and 2008, global inequality decreased for the first time in almost 200 years, when measured using individual income and not average incomes within countries. Economic growth and improvement in real incomes in China and India have been essential to the decrease in global inequality. In addition, a Pew Research Center study found that the share of the global population considered poor declined from 29 percent in 2001 to 15 percent in 2011.

However, the average income of nearly half the world's population is $\$ 4,035$ a year or less, according to world development indicators, statistics that are compiled by the World Bank.

But over the last four decades, inequality grew within most developed countries as gains in wealth and income were increasingly concentrated at the top, according to the World Wealth \& Income Database. In other words, the rich got richer in much of the developed world. In that regard, the Oxfam report is right on target.

Rising inequality is not necessarily a benign trend, as we documented last year in a report for the RAND Corporation. Research has shown that economic mobility - the ability to move up the income ladder - has been declining, at least in the United States, and that high inequality, as well as related factors such as segregation by race and income, are all associated with declining mobility.

\footnotetext{
${ }_{1}^{1}$ Amaral EFL, Price CC. 2017. "Too entertaining to be true: Recent headlines declaring eight men are as wealthy as half the world misrepresent trends in inequality." U.S. News \& World Report, February 6, 2017. (U.S. News link)
} 
The world doesn't have to accept such income and wealth disparities. Public policies can reduce income inequality and improve economic mobility. For instance, improving access to quality education has been shown to increase income later in life. Health insurance and affordable health care reduces financial risk associated with illness. Cash benefits for lowincome families can break the links between income inequality and economic mobility.

Of course, not all policies that affect inequality will have the same impact on mobility. Some may directly reduce income inequality but only indirectly provide mobility (by benefiting the next generation, for instance). Other policies, such as those affecting children and education, may directly impact economic mobility (such as free preschool programs or affordable higher education) but have little or no impact on income inequality.

In an "everything is reduced to a sound-byte era," news coverage of the Oxfam report may lead the public and policymakers to mistakenly believe that global inequality has been rising instead of falling. Rising inequality is a trend occurring within countries, and policies are needed to address that.

Any time a complicated economic issue is reduced to an attention-grabbing headline, the reader should pause and consider: Is it too entertaining to be true?

Ernesto F. L. Amaral (eflamaral@gmail.com), Contributor

Ernesto F.L. Amaral is an associate sociologist at the nonprofit, nonpartisan RAND Corporation.

Carter C. Price (price@rand.org), Contributor

Carter C. Price is a mathematician at the nonprofit, nonpartisan RAND Corporation. 